TEACHING TACTIC

\title{
Using Visuals as an Entry Point to Theological Conversation
}

Mary DeBroeck
Strake Jesuit College Preparatory

The context

This activity was used in introductory courses in theology at a Catholic institution, with class sizes ranging from eighteen to twenty-five. The strategy can be used for a discussion portion of a class or for an entire session.

\section{The pedagogical purpose}

The goal of this activity is to encourage students to engage critically with several texts of a theological tradition, to recognize varying perspectives and genres in the history of theology, and to compare different texts constructively in small groups through analysis of an image. It is intended to elicit theological conversation rather than a more conventional critical analysis of the chosen image, although a scholarly reading on an interpretation of the image could be a fruitful follow-up to the discussion.

\begin{abstract}
Description of the strategy
Disseminate several different readings on a topic for students to read for the intended class session. These readings can represent different genres (Biblical exegesis, Patristic texts, Scholastic theology, and so forth), a single corpus of one author, or various Christian traditions. In class divide students into groups based on an equal distribution of texts, so that every text is represented in each group and each group receives the visual image without comment. Many options are possible in the selection of what image is used: a classic or contemporary work of art, a drawing, a map or diagram, or architectural designs, to name a few. Two examples of images which have been successful are a map of Dante's Inferno in a discussion on the nature of sin and Michelangelo's Sistine Chapel Ceiling in the context of the human person and the Fall. Students are then challenged to interpret this image theologically in light of their assigned reading, considering questions such as: How can this image be theologically interpreted? What would "your" author say regarding this image? What themes from the reading are in harmony or in conflict with this image? A similar strategy can be arranged by organizing groups according to the same text and presenting their analysis to the class before a discussion.
\end{abstract}

\section{Why it is effective}

The visual representation evokes curiosity and becomes a useful entry-point to a theological discussion especially when the readings or topic are intimidatingly dense. With the image as the center of discussion, it allows the instructor then to navigate the class as novices toward a deeper appreciation not only for theological interpretation of images, but also for theological nuance and development, the diversity of the tradition, the limitedness of single perspectives, and the strengths and weaknesses of different theological genres in conveying theological truths. 